Research Article

\title{
Me Time, or We Time? Age Differences in Motivation for Exercise
}

\section{Crystal N. Steltenpohl, PhD, ${ }^{1, *}$ Michael Shuster, PhD, ${ }^{2}$ Eric Peist, BA, ${ }^{2}$ Amber Pham, BA, ${ }^{2}$ and Joseph A. Mikels, PhD²}

'Department of Psychology, University of Southern Indiana, Evansville. ${ }^{2}$ Department of Psychology, DePaul University, Chicago, Illinois.

\begin{abstract}
*Address correspondence to: Crystal N. Steltenpohl, PhD, Department of Psychology, University of Southern Indiana, Liberal Arts 3046, 8600
\end{abstract} University Boulevard, Evansville, IN 47712. E-mail: cnsteltenp@usi.edu

Received: December 12, 2017; Editorial Decision Date: March 23, 2018

Decision Editor: Barbara J. Bowers, PhD

\begin{abstract}
Background and Objectives: Increasing exercise continues to be an important health issue for both older and younger adults. Researchers have suggested several methods for increasing exercise motivation. Socioemotional selectivity theory (SST) posits that people's motivation shift from future-oriented instrumental goals to present-oriented emotionally meaningful goals as we age, which provides insight into how people's motivations for exercise may differ for older versus younger adults. The aim of our study was to examine how exercise motivation differs for older versus younger adults.

Research Design and Methods: Older (greater than 59 years old) and younger (aged 18-26 years) adults participated in focus groups. They discussed exercise motivation (or lack thereof), motivators and barriers to exercise, and preferences about when, where, and with whom they exercise. Focus group transcripts were analyzed using direct content analysis and iterative categorization.

Results: Consistent with SST, younger adults generally preferred to exercise alone to achieve instrumental fitness goals, whereas older adults preferred to exercise with others. Additionally, older adults tend to consider peripheral others (e.g., strangers, acquaintances), as a positive rather than a negative influence.

Discussion and Implications: SST provides a framework for exploring age-related shifts in exercise motivation. Additionally, the positivity effect was reflected in how older adults evaluated the influence of peripheral others. Motivational messages could be tailored to increase health behavior changes by focusing on instrumental exercise goals for younger adults and exercise focused on meaningful relationships for older adults.
\end{abstract}

Keywords: Focus groups, Life span, Positivity effect, Socioemotional selectivity theory

The important preventative behavior of exercise has been linked to improved physical health (Emery \& Gatz, 1990; Hillman, Erickson, \& Kramer, 2008). For older adults especially, exercise has been linked to benefits in physical functioning such as better breathing, increased muscle strength, flexibility and balance, as well as less susceptibility to falls and improved executive control processes (Colcombe \& Kramer, 2003; Cress et al., 1999; Howe, Rochester, Neil, Skelton, \& Ballinger, 2011; Liu \& Latham, 2009;
Sherrington et al., 2011; Whitehead \& Blaxton, 2017). Despite these benefits, $40.3 \%$ of adults aged $18-44$ years and $59.4 \%$ of adults aged 65 years and older do not meet aerobic activity nor muscle strengthening guidelines (National Center for Health Statistics, 2015).

People are motivated to exercise for various reasons; some motivators relate to the self-focused reasons (e.g., having personal goals, etc.; Dacey, Baltzell, \& Zaichkowsky, 2008; Eyler et al., 1998; Wolinsky, Stump, \& Clark, 1995). 
Other motivational factors involve social interaction (e.g., connecting with others, Buman, Yasova, \& Giacobbi, 2010; Eyler et al., 1998; Wolinsky et al., 1995). These studies suggest motivation to exercise can come from within oneself, but can be equally impacted by social contexts.

How motivation to exercise shifts with advancing age is not fully understood. Research has found that younger adults enjoy exercising alone more than with others (Crust, Swann, Allen-Collinson, Breckon, \& Weinberg, 2014; Plante, Gustafson, Brecht, Imberi, \& Sanchez, 2011), which could impact motivation to exercise. Younger and middle-aged adults tend to exercise to work on personal goals and compete with oneself (Crust et al., 2014). In contrast, meaningful others (e.g., friends and family) can serve as a motivation to engage in exercise for older adults (Buman et al., 2010; Dacey et al., 2008; Dionigi, Horton, \& Baker, 2013). Motivation to exercise can be affected by the presence of peripheral others; that is, people one does not know very well. Although group exercise can be beneficial for older adults wishing to improve balance, flexibility, and strength (Hughes et al., 2004; Yan, Wilber, Aguirre, \& Trejo, 2009), it remains unclear if and how peripheral others influence motivation. Importantly, there has been limited research on socially embedded exercise motivation examining self-focused versus other-oriented goals (e.g., McPhate et al., 2016; Simek et al., 2015).

Psychologically, motivation is regularly intertwined with emotion; previous research suggests positive affective responses to messages highlighting the benefits of an activity may lead to positive changes in attitudes and ultimately greater behavioral intentions and preventative behaviors, such as exercise (Ajzen, 1985; Rothman \& Salovey, 1997). From an adult life-span perspective, there are important differences in how older and younger adults respond to stimuli. In contrast to the predominant and largely adaptive psychological negativity bias associated with younger adulthood (Baumeister, Bratslavsky, Finkenauer, \& Vohs, 2001), older adults prefer positive experiences and emotions (Carstensen \& Mikels, 2005; Mikels, Reed, Hardy, \& Löckenhoff, 2014; Mikels et al., 2016). This pattern is known as the positivity effect. As such, adult age-related differences in motivation and emotion may influence how people of different ages approach health-related information. Socioemotional selectivity theory (SST) proposes that with advancing age, the relative importance of goals shifts as a function of future time perspective (Carstensen, 2006; Carstensen, Isaacowitz, \& Charles, 1999). According to SST, younger adults focus more on future-oriented and horizonexpanding goals like acquiring knowledge, whereas older adults focus more on present-oriented and emotionally meaningful goals such as maintaining high quality social bonds. Although these goals are by no means absolute or nonoverlapping, SST provides a context from which we can consider age differences in exercise motivation.

Using SST as a framework for understanding potential shifts in socially-related exercise motivation, younger adults may be more motivated by self-focused reasons to exercise, whereas older adults may exhibit greater otherfocused motivation to exercise. Our aim was to examine and compare differences in how older and younger adults describe their exercise motivation (or lack thereof) and under what conditions (e.g., place, activities, partners, etc.) they exercised.

\section{Design and Methods}

To examine age differences in exercise motivation, focus groups, which ranged from three to eight participants in size, were conducted from May 2015 to May 2016 by three researchers: one moderator and two note takers. All moderators and note takers underwent a 2-hr training before involvement with the focus groups, and at least one researcher with previous focus group experience was at each focus group session. The moderator sat with the focus group participants and talked with them, while the note takers sat on opposite sides of the room, outside of the focus group circle. The notes were used to aid with transcription efforts.

\section{Participants}

Seventy-eight participants were recruited for focus groups, of which 39 were older adults (greater than 59 years old) and 39 were younger adults (aged $18-26$ years); see Table 1 for demographic information.

\section{Procedure}

Potentially interested older adults were reached via flyers posted at a local senior center. Younger adults were recruited from the university introduction to psychology course research subject pool and the community. Research subject pool participants received course credit for participation, whereas community participants received compensation of $\$ 20-\$ 30$.

After obtaining ethical approval from our internal review board, we conducted eight focus groups with younger adults and seven focus groups with older adults. Participants were divided based on their activity levels (less than or more than three times per week) to provide the best opportunity for open, honest discourse without fear of being judged and so that individual responses would not be biased by the presence of individuals with different exercise patterns. Participants were also given name tags to encourage involvement and to allow participants to respond to one another more easily.

After obtaining informed consent and informing participants that the focus groups would be audio recorded, participants were asked about their general feelings about and impressions of exercise, exercise motivations (or lack thereof), and barriers to exercise. Participants also shared their preferences about when, where, and with whom they exercise. 
Table 1. Demographic Characteristics of Participants by Age

\begin{tabular}{lcc}
\hline$N=78$ & $\begin{array}{c}\text { Young adults } \\
(N=39)\end{array}$ & $\begin{array}{c}\text { Older adults } \\
(N=39)\end{array}$ \\
\hline $\begin{array}{l}\text { Age, } M(S D) \\
\text { Sex }, N(\%)\end{array}$ & $20.23(1.9)$ & $69.82(8.2)$ \\
Female & & $26(66.7)$ \\
Male & $30(76.9)$ & $13(33.3)$ \\
Race, $N$ (\%) & $9(23.1)$ & $1(2.6)$ \\
Asian/Pacific Islander & $5(12.8)$ & $16(41.0)$ \\
Black & $5(12.8)$ & $1(2.6)$ \\
Latinx & $1(2.6)$ & $21(53.8)$ \\
White & $24(61.5)$ & $0(0.0)$ \\
Other & $4(10.3)$ & $13(33.3)$ \\
SES, $N$ (\%) & & $7(17.9)$ \\
Lower & $2(5.1)$ & $17(43.6)$ \\
Lower-Mid & $7(17.9)$ & $2(5.1)$ \\
Middle & $17(43.6)$ & $0(0.0)$ \\
Upper-Mid & $12(30.8)$ & \\
Upper & $1(2.6)$ & \\
\hline
\end{tabular}

Notes: SES = Socioeconomic Status.

\section{Data Analysis}

Because this study is theoretically based on the tenets of SST, the transcripts were analyzed using a mixture of directed content analysis (Hsieh \& Shannon, 2005) and iterative categorization (Srivastava \& Hopwood, 2009). Directed content analysis has been used to analyze focus group data across age groups while drawing on existing theory (Löckenhoff et al., 2013). Such an approach involved developing a code manual a priori, based on previous research and theory. Following this approach, the authors created three broad categories: the role of meaningful others, self-focused motivations to exercise, and peripheral social factors. These categories were given operational definitions (Table 2) that were then discussed with the coders and modified as needed (one revision cycle).

Because these three categories were derived from previous theory, they were tested for reliability and applicability to raw information. The audio recordings were transcribed and, using NVIVO, the coders independently coded two randomly-selected focus group transcripts (one older adult and one younger adult), highlighting all sentences appearing to fit under each of the categories. Initial consistency indices ranged between $79 \%$ and $90 \%$ between the two coders on each of the categories. The results were then compared and discussed. No major modifications to the category definitions were required and allowed the researchers to come to a mutual understanding of how inclusive the categories should be. Finally, the two coders independently coded each transcript based on these three categories.

The coders then independently recoded those transcripts utilized to establish reliability. Once this was completed, the authors and coders met to discuss each category to ascertain subcategories for each theme, allowing the subthemes to emerge from the data. Through coding meetings,
Table 2. A PrioriThemes and Operational Definitions

\begin{tabular}{llc}
\hline Theme & Operational Definition & $\kappa$ \\
\hline Meaningful others & $\begin{array}{l}\text { Statements indicating exercise } \\
\text { preferences or motivation to spend } \\
\text { time with family, friends, or other } \\
\text { loved ones. }\end{array}$ & 0.84 \\
Self-focus & $\begin{array}{l}\text { Statements indicating preferences } \\
\text { or motivation for exercising by } \\
\text { oneself. }\end{array}$ & 0.86 \\
Peripheral others & $\begin{array}{l}\text { Statements indicating exercise } \\
\text { preferences or motivation based } \\
\text { on others who one does not neces- } \\
\text { sarily know personally (i.e., stran- } \\
\text { gers, people at the gym, etc.) }\end{array}$ & \\
\hline
\end{tabular}

team members established relevant subthemes through consensus. Each subtheme was discussed and definitions were formed to gain a better understanding of older and younger adults' motivations to exercise. Once these subthemes were created, the coders reviewed the quotes from transcripts that were coded on the three major themes and identified their subcategory. One coder would code for the subthemes under each category, and then another coder would validate their codes. The research team met regularly to ensure resolution of all disputes through consensus. Tallies were created representing the number of times each subtheme was mentioned in older and younger adult focus groups. These tallies guided the team's exploration of the similarities and differences in the themes and subthemes.

\section{Results}

Three major themes emerged from the focus groups: meaningful others, self-focus, and peripheral others. The meaningful others theme involved how family and friends impact people's exercise motivations. The self-focus theme centered on desires for people being alone or focusing on the self. The peripheral others theme reflected the role of strangers and acquaintances in exercise. Although our analysis of these themes will refer to general trends, it is important to note individual variation in preferences.

\section{Meaningful Others}

This subtheme emerged in discussions about how friends and family played a significant role in participants' motivation to exercise. Older and younger adults were motivated by family members and friends, yet the two groups discussed the motivational benefits of meaningful others very differently. Overall, older adults considered meaningful others as providers of social experiences. In contrast, younger adults disproportionately viewed meaningful others as instrumental to achieving their exercise goals (i.e., in a selffocused manner). The following subthemes emerged which highlight these differences: (1) providing exercised-based 
opportunities for social interaction, and (2) supporting exercise goals.

\section{Opportunities for Social Interaction}

Whether it was spending time with a significant other, making new friends, or exercising to keep up with meaningful others, exercise served as a method of social interaction across both age groups. Compared to younger adults, twice as many older adults mentioned being motivated to exercise to interact with family and friends or to discuss the fun and enjoyment of exercising with meaningful others. One older adult stated,

Well, I really would have to say I would enjoy (exercise) more with a group of friends, uh, definitely a more social setting I would enjoy more. So that form of exercise would not only be beneficial to me physically, but that would be beneficial to me emotionally and spiritually. Because I really enjoy being around people. But only certain kinds of people. [Group laughter] Some people I don't like being around at all.

Similarly, another older adult mentioned, "I have camaraderie with that fun and exercise." Another mentioned, "I'm a widow and I have a companion and we do ballroom dancing every Friday and I really enjoy that, I think it's the best exercise possible because it's fun, people look so happy."

When discussing the benefits of exercise, older adults often mentioned social interaction. For instance, one older adult said, "I think it's always fun to be with, you know, with your friends." When discussing the consequences of not exercising, one older adult listed the social and emotional costs of not engaging in exercise, stating one who does not exercise would "feel bad and become isolated in your house" and would "lose contact with some friends that you had activities with before."

Moreover, unlike younger adults, older adults emphasized how exercise was a way to make new meaningful connections. One older adult said,

As far as networking opportunities... it allows me to meet people that are doing what I do... it increases your whole social network and at the same time gives us those positive benefits. Might even meet somebody and get married.

Another older adult described a fond memory of how his exercise behavior leads to a romantic relationship,

In fact, I have a happy memory of deciding, oh, I have a lot of energy today, let me get on my bicycle. I was riding along and came up to the tennis court there in the park and I met the most wonderful man and we had a five-year relationship.

To a lesser extent, younger adults also mentioned having social motives to exercise, yet these types of statements were exceptions to the rule. For instance, a younger adult described how exercise allowed her to spend time with her brother,
Yeah, it's definitely bonding... I have a younger brother, he's nine... he always likes exercising with me at home and it's a time where he doesn't even care what we're doing. He just cares that we're doing it together.

Importantly, when younger adults discussed social benefits pertaining to exercising with meaningful others, they discussed the instrumental role of friends and family for exercise behavior. For instance, one younger adult explained,

When my friends want to go... I know it's not technically... hanging out but it's an excuse to talk to friends too. So then when my friends go to the gym we'll all go together and then we do it and then it becomes more of a routine thing to do all the time.

\section{Supporting Exercise Goals}

For both older and younger adults, the subtheme of supporting exercise goals emerged in discussions about exercising with meaningful others. Although both age groups regarded friends and family members as important facilitators for achieving personal exercise goals, younger adults discussed such statements over three times as often as older adults. Younger adults stressed meaningful others helped them achieve instrumental goals through initiating joint exercise behavior, promoting adherence to routines, and providing instrumental support.

Younger adults often discussed how meaningful others helped to initiate exercise behavior or to hold younger adults accountable for regular exercise. For example, a young woman described,

I feel like it is motivating, if I tell my friend... that I decided to go to the gym... four times a week and if I don't go she'll be like, 'Oh, weren't you supposed to go to the gym today?' and so I'll kind of feel guilty about myself if I don't. So it's kind of like... telling someone about it can be motivating I think.

Moreover, younger adults often discussed how meaningful others provided instrumental support by conveying expert knowledge, helping facilitate safe and challenging workouts and making them feel comfortable in group exercise contexts. When discussing doing a difficult weight lifting exercise a younger adult explained, "You can push yourself much harder with someone spotting you." Younger adults also described how exercising with a friend made them feel comfortable at a gym.

Although some older adults mentioned similar instrumental benefits of exercising with meaningful others, their discussions still emphasized the fun and general social benefits. Another older adult mentioned,

I think it's always fun to be with, you know, with your friends, and then especially if you're with your friends and you're walking or something, you don't notice that you're walking or if you've been someplace or how far you've walked. 
Exercising with others also provided many older adults with a means for improving one's health outcomes. Regarding their need for external social motivation, an older adult explained,

I need a plan on what I want to learn so I need the motivation of a learning experience. I can also intensify my improvement and abilities by doing it with one other person. It doesn't have to be the same person it can be different people. But, I had a partner for 12 years and that really improved everything, her availability, but you know she's not available anymore and I have to deal with it but I probably wouldn't have gotten advanced if it wasn't for her.

Regarding discussions of meaningful others, older adults emphasized exercise was an opportunity for social interaction and stressed exercising with friends was fun and enjoyable. Older adults also viewed exercise as an opportunity to promote close personal connections and even make new ones. Conversely, younger adults tended to emphasize how meaningful others facilitated goal-directed exercise behavior (i.e., exercise initiation, accountability, and instrumental support) much more frequently than they discussed how their friends or family made exercising more enjoyable.

\section{Self-focus}

Participants often discussed working out alone, but the way in which younger adults discussed this practice differed in meaningful ways from older adults. Relative to the motivations of older adults, younger adults demonstrated a preference to work out alone that stemmed from their desire to focus on themselves ("Me time") and have the freedom to exercise as they pleased ("Autonomy"). On the other hand, older adults generally expressed a desire to work out alone much less often, but when they listed reasons to exercise by themselves, they referenced autonomy.

\section{Me Time}

This subtheme emerged as participants referenced desires to exercise without others. In this context, exercise is seen to focus on oneself without socializing or interacting with others. In general, younger adults explicitly stated they preferred to work out alone far more often than older adults. Younger adults mentioned this preference over 30 times across the focus groups and emphasized exercise was their time in the day to "zone out" and not think about things such as school, family, and friends. When it came to one's own fitness, younger adults tended to explain that exercise was a time for meeting goals and focusing on oneself. One younger adult stated,

I can't run with other people 'cause I think, I like use it as "me time" so like I can get my stress out and just focus on myself. Trying to have a conversation while you're running five miles isn't the best thing to do, so I like to run outside by myself.
On the other hand, some older adults mentioned they exercised by themselves, but few indicated this was their preference. Commonly, older adults who worked out alone did so because they did not have regular access to exercise partners. One older adult noted, "For me in any capacity, getting out riding, in any capacity, or walking alone. Well, I really would have to say I would enjoy more with a group of friends, uh, definitely a more social setting I would enjoy more."

\section{Autonomy}

This subtheme centered on the ability for participants to adapt their workout to their liking when they exercised alone. Many younger adults expressed a desire to control their own exercise behaviors. Some younger adults preferred developing their own workouts without having to worry about what a workout partner may want to do.

Additionally, for some younger adults, working out with other people was a distraction and an active hindrance to autonomy. As another younger adult passionately told the group,

I hate working out with friends. Oh my god it drives me crazy. 'Cause that's like your way, you kind of have to time everything differently depending like on them, and that changes everything. I want to have [...] freedom...

Younger adults felt working out with others hampered their own exercise, as they were less able to focus on their goals. Younger adults preferred to exercise alone so they would not feel obligated to talk to anyone else and could instead pay attention to their own physical activity. Younger adults even shared strategies they employed to work out alone. For example, one younger adult ran outside to avoid seeing people she knew. Another younger adult regularly runs on a treadmill near the gym's window so she could look out the window instead of at other people in the gym. Although younger adults generally preferred to exercise alone, there were instances when they did express a desire to exercise with others-especially when it served self-focused instrumental goals, which are further discussed below.

Older adults, on the other hand, very rarely expressed a desire to minimize distractions. The few older adults who reported preferring to work out alone, like younger adults, did so to stay at their own pace or routine and were not pressured to work at the same pace as someone else. For example, one older adult mentioned, "I'm usually alone, I usually kinda have my own pace, my own rhythm, and I also kind of like to get into, there's kind of I think everybody can relate to this is, kind of a mental groove." It is important to note few older adults expressed this preference.

These results suggest younger and older adults generally have different preferences for working out alone, both in quantity and content. Younger adults prioritized being alone to prioritize "me time" and increase autonomy through minimizing social distractions. Older adults, however, rarely expressed a preference for working out alone 
and when they did mention working out alone, it was often because they lacked regular access to an exercise partner, or preferred to exercise at their own pace.

\section{Peripheral Others}

In addition to discussing motivations to exercise alone and with meaningful others, many participants discussed how peripheral others (e.g., strangers, acquaintances) motivated their exercise behaviors. Peripheral others determined participants' exercise motivations and sometimes influenced where they chose to exercise. Subthemes include exercising in a social context and social evaluation.

\section{Exercising in Social Contexts}

Older and younger adults discussed their reasoning for exercising around peripheral others. The most frequently mentioned social contexts were the gym, group classes, and team sports.

Both age groups discussed the instrumental benefits (e.g., competition, accountability, and "energy") of exercising in social settings at similar rates. For instance, a younger adult enjoyed exercising with others if it benefited her exercise goals: "I... enjoy classes, but not specifically with my friends, but just with other people. And having that environment and a teacher to be like, 'You can do it.' That's awesome to me." Several younger adults spoke specifically about peripheral others as self-focused instrumental motivators. For instance, one younger adult explained,

I kind of like the motivation of seeing everyone else working around me working out too, like, I kind of need it. I'm not a competitive person at all except when it comes to like working out. ... I like being at the (college gym) seeing other people doing the same thing where they're working out and they're putting themselves through the same physical torture that it is to like work out and then it makes you want to do well too because other people are doing the same thing.

Older adults made similar statements regarding instrumental reasons for exercising with peripheral others such as, "If you're doing something like a Zumba class of course you're with a group and you're energized by the group activity..." and, "...you have that competition too. No one wants you to cheat."

However, the age groups significantly diverged in the rate at which they discussed the social benefits of exercising around peripheral others. When discussing peripheral others, very few younger adults mentioned that they enjoyed the social benefits of exercising in gyms or classes around peripheral others. Conversely, across the older adult groups, there were about two dozen older adults who made statements regarding their preference for exercising around peripheral others. Older adults made statements such as, "I don't like being on a treadmill in a gym. So yeah, reaching out and being with people is important to me," and, "I need the group... I also enjoy the camaraderie that comes with it." When describing the benefits of exercise, older adults often cited social rewards. One older adult mentioned, "I would say to exercise with a group of people rather than on your own uhm, because you have that company." Additionally, when describing the consequences of not exercising the same older adult mentioned "less social contact" and "loneliness."

Moreover, many older adults emphasized motivation to exercise for opportunities to socialize with peripheral others. For instance, when discussing their engagement in exercise classes one older adult said, "My motivation is that uh, well first of all (to) socialize." Another older adult explained,

My particular activity has to be done with people. That's why partner dancing for me is important, not line-dancing, or exercising by myself. It's actually touching and relating, and participating in a group as well as with a partner and having responsibility for somebody. And not having a family, this takes place of that.

\section{Social Evaluation}

This subtheme pertained to participants' perceptions of peripheral others' evaluations and how such evaluations impacted exercise behaviors and motivations to exercise. Older and younger adults drastically differed in how they described social evaluations made by peripheral others.

Concern with how others viewed and evaluated an individual's exercise was common among younger adults and was associated with their aversion to exercising around peripheral others. One younger adult explained,

And if I run in public, I don't really like it, because I don't like being honked at and stuff.

So I actually don't like exercising in public... But when I do go to the gym, I go late at night, because I don't want people being around, because they stare at you and it's weird. Like, I shouldn't be self-conscious, but I am, because people are watching you do the machine wrong or something, and people have come over to me and told me how to do it, and I'm just like, I'm not asking for help.

Younger adults talked about wanting to exercise without experiencing others' ridicule or judgment, and some even mentioned choosing to exercise alone to avoid this experience. A younger adult said, "I much rather be outside kind of away from everyone else exercising 'cause you feel out of place when you don't know what you're doing. I like to get in my own little zone to do what I want to do."

Whereas only a couple of older adults were negatively affected by social evaluation, relative to the young, many more older adults were motivated by hearing peripheral others' positive evaluations. Older adults made statements such as, "I just love to hear individuals tell me you don't look like 
that age...[It's] motivation... getting compliments from people...[for] the things I like to do," and, "Those wonderful comments that you hear from people saying, 'You really do look 25." Other comments included, "They tell me that they wouldn't think I was as old as I am. That I appear younger to them," and, "It's always nice to hear when somebody says, 'Oh, I see you've lost a little weight." Another older adult mentioned an incident when a stranger complimented them. "... He said in my country a guy your age would be lying on the couch. I felt kinda good about that, I was walking kind of high. I was like, 'Oooh that's nice."”

Older and younger adults cited very different influences of peripheral others on their motivations to exercise and preferences for exercising in public. Although both age groups acknowledged the instrumental benefits of exercising in social contexts, older adults cited positive social benefits to a much greater extent than their younger counterparts. Moreover, when discussing the evaluations of peripheral others, relative to older adults, younger adults described a much greater concern for negative evaluations from strangers. Conversely, older adults' discussions of social evaluations mostly focused on the motivating nature of the positive compliments made by peripheral others.

\section{Discussion and Implications}

This study explored motivation to exercise as conveyed by older and younger adults. Consistent with SST (Carstensen, 2006), which posits that as we age, our motivation shifts from future-oriented and instrumental goals to more present-focused and emotionally meaningful goals, our findings revealed distinct age-related prioritizations of social factors in motivations to exercise. Although there was diversity and overlap in self- versus other-focused preferences among both older and younger adults, they tended to respond in ways that align with the tenets of SST. Younger adults placed more weight on self-related motivations to exercise ("me time"), whereas older adults focused on exercise as a social experience ("we time"). Specifically, younger adults generally preferred to exercise alone so they could focus on fitness goals, and meaningful others further helped them achieve these instrumental fitness goals. Older adults, on the other hand, generally referenced social motivators to exercise, emphasizing maintaining and fostering relationships with meaningful others and increasing opportunities for socializing.

Regarding emotional factors, the peripheral others theme reflected the positivity effect, in which older versus younger adults focus more on positive versus negative information (see Reed, Chan, \& Mikels, 2014) and interpret ambiguous information in a generally positive rather than negative light (Mikels \& Shuster, 2016). In our study, older adults considered the presence and influence of (similarly aged) peripheral others positively. Younger adults, on the other hand, did find peripheral others motivating at times, but also expressed negativity regarding the presence and influence of peripheral others relative to the older adults.

\section{Strengths and Limitations}

To create an atmosphere where participants felt comfortable with expressing their opinions, we grouped participants by their exercise habits, operationalized in this study by number of exercise sessions a week. Whereas in quantitative research, categorizing continuous variables can result in a loss of information (van Walraven \& Hart, 2008), in this study we controlled for this factor and thus were able to create an environment minimizing the influence of social desirability bias and allowing participants to interact with one another without observed restrictions (Breen, 2006).

Importantly, our focus groups took place in a large metropolitan area with access to a large array of leisure and exercise activities, and with individuals who were generally already going out and participating in social activities. Previous research suggests those who live in rural areas have different facilitators and barriers to exercise (Parks, Housemann, \& Brownson, 2003; Wilcox, Castro, King, Housemann, \& Brownson, 2000). It would be interesting for future research to examine whether the same patterns emerge in a rural sample and among older and younger adults who are not currently socially well-connected or have limited opportunities for social connections. Although future research should extend the scope of this work and further examine the mechanisms by which the current relationships occur, there are a few implications that could guide the creation of health messages.

\section{Future Directions}

These findings suggest that messages aimed at increasing physical activity could be tailored to the socially-oriented preferences and motivations of older and younger adults. Researchers and health professionals may be able to use our findings to tailor motivational messaging to promote health behavior interventions targeting either older or younger adult populations. Specifically, there may be applications for using age-specific messages to improve exercise initiation, adherence, and maintenance. Programs targeting younger adults may focus on instrumental goals toward achieving self-focused purposes for exercise. Programs targeting older adults may focus on exercise to maintain meaningful relationships. For both groups, other messages could be effective that emphasize topics such as looking better, feeling stronger, or being able to complete exerciserelated goals like running a $5-\mathrm{km}$ run or marathon.

Additionally, an appreciation of age-related differences in motivation pertaining to exercise can be utilized by service providers to attract certain populations to gyms or exercise programs. Younger adults may be more attracted to exercise centers promoting goal achievement and less distraction. For example, gyms offering a wide array of exercise machines may be more appealing to younger adults than gyms offering primarily group classes. Older adults may be more attracted to exercise centers promoting group activities, such as Zumba classes, allowing older adults to meet new people. 
These findings extend the literature on health message framing for older and younger adults. Our data suggest age-related differences in social motivation surrounding exercise behaviors align with life-span theory. Our findings reveal that younger adults see exercise as "me time," or a chance to work on one's own health-related goals, whereas older adults see exercise as "we time," or an opportunity to create and maintain relationships. Applying life-span theories, specifically SST and the positivity effect, to exercise and health messaging holds promise to help create more effective messages targeting individuals of various ages.

\section{Funding}

This research was partially supported by the National Institute on Aging (grant R01-AG043533) and by the National Science Foundation (grant SES-1139554), awarded to J. A. Mikels. The content is solely the responsibility of the authors and does not necessarily reflect the official views of the National Institutes of Health, the National Science foundation, or their affiliates.

\section{Conflict of Interest}

None reported.

\section{References}

Ajzen,I.(1985). From intentions to actions: A theory of planned behavior. In J. Kuhl \& J. Beckmann (Eds.), Action control (pp. 11-39). Heidelberg, Berlin: Springer. doi:10.1007/978-3-642-69746-3_2

Baumeister, R. F., Bratslavsky, E., Finkenauer, C., \& Vohs, K. D. (2001). Bad is stronger than good. Review of General Psychology, 5, 323-370. doi:10.1037/1089-2680.5.4.323

Breen, R. L. (2006). A practical guide to focus-group research. Journal of Geography in Higher Education, 30, 463-475. doi:10.1080/03098260600927575

Buman, M. P., Yasova, L. D., \& Giacobbi, P. R. (2010). Descriptive and narrative reports of barriers and motivators to physical activity in sedentary older adults. Psychology of Sport and Exercise, 11, 223-230. doi:10.1016/j.psychsport.2010.02.002

Carstensen, L. L. (2006). The influence of a sense of time on human development. Science, 312, 1913-1915. doi:10.1126/ science. 1127488

Carstensen, L. L., Isaacowitz, D. M., \& Charles, S. T. (1999). Taking time seriously: A theory of socioemotional selectivity. The American Psychologist, 54, 165-181.

Carstensen, L. L., \& Mikels, J. A. (2005). At the intersection of emotion and cognition: Aging and the positivity effect. Current Directions in Psychological Science, 14, 117-121. doi:10.1111/j.0963-7214.2005.00348.x

Colcombe, S., \& Kramer, A. F. (2003). Fitness effects on the cognitive function of older adults: A meta-analytic study. Psychological Science, 14, 125-130. doi:10.1111/1467-9280.t01-1-01430

Cress, M. E., Buchner, D. M., Questad, K. A., Esselman, P. C., deLateur, B. J., \& Schwartz, R. S. (1999). Exercise: Effects on physical functional performance in independent older adults. The Journals of Gerontology, Series A: Biological Sciences and Medical Sciences, 54, M242-M248. doi:10.1093/gerona/54.5.m242

Crust, L., Swann, C., Allen-Collinson, J., Breckon, J., \& Weinberg, R. (2014). A phenomenological exploration of exercise mental toughness: Perceptions of exercise leaders and regular exercisers. Qualitative Research in Sport, Exercise and Health, 6, 441-461. doi:10.1080/2159676x.2014.901986

Dacey, M., Baltzell, A., \& Zaichkowsky, L. (2008). Older adults' intrinsic and extrinsic motivation toward physical activity. American Journal of Health Behavior, 32, 570-582. doi:10.5555/ajhb.2008.32.6.570

Dionigi, R. A., Horton, S., \& Baker, J. (2013). Negotiations of the ageing process: Older adults' stories of sports participation. Sport, Education and Society, 18, 370-387. doi:10.1080/1357 3322.2011.589832

Emery, C. F., \& Gatz, M. (1990). Psychological and cognitive effects of an exercise program for community-residing older adults. The Gerontologist, 30, 184-188. doi:10.1093/geront/30.2.184

Eyler, A. A., Baker, E., Cromer, L., King, A. C., Brownson, R. C., \& Donatelle, R. J. (1998). Physical activity and minority women: A qualitative study. Health Education \& Behavior, 25, 640-652. doi:10.1177/109019819802500510

Hillman, C. H., Erickson, K. I., \& Kramer, A. F. (2008). Be smart, exercise your heart: Exercise effects on brain and cognition. Nature Reviews Neuroscience, 9, 58-65. doi:10.1038/nrn2298

Howe, T. E., Rochester, L., Neil, F., Skelton, D. A., \& Ballinger, C. (2011). Exercise for improving balance in older people. Cochrane Database of Systematic Reviews, 11. Art. No.: CD004963. doi:10.1002/14651858.CD004963

Hsieh, H. F., \& Shannon, S. E. (2005). Three approaches to qualitative content analysis. Qualitative Health Research, 15, 12771288. doi:10.1177/1049732305276687

Hughes, S. L., Seymour, R. B., Campbell, R., Pollak, N., Huber, G., \& Sharma, L. (2004). Impact of the fit and strong intervention on older adults with osteoarthritis. The Gerontologist, 44, 217228. doi:10.1093/geront/44.2.217

Liu, C. J., \& Latham, N. K. (2009). Progressive resistance strength training for improving physical function in older adults. Cochrane Database of Systematic Reviews, 3. Art. No.: CD002759. doi: 10.1002/14651858.cd002759

Löckenhoff, C. E., Laucks, S. S., Port, A. D., Tung, J., Wethington, E., \& Reid, M. C. (2013). Temporal horizons in pain management: Understanding the perspectives of physicians, physical therapists, and their middle-aged and older adult patients. The Gerontologist, 53, 850-860. doi:10.1093/geront/gns136

McPhate, L., Simek, E. M., Haines, T. P., Hill, K. D., Finch, C. F., \& Day, L. (2016). “Are Your Clients Having Fun?” The implications of respondents' preferences for the delivery of group exercise programs for falls prevention. Journal of Aging and Physical Activity, 24, 129-138. doi:10.1123/japa.2014-0168

Mikels, J. A., Reed, A. E., Hardy, L. N., \& Löckenhoff, C. E. (2014). Positive emotions across the adult life span. In M. M. Tugade, M. N. Shiota, \& L. D. Kirby (Eds.), Handbook of positive emotions (pp. 256-271). New York, NY, US: Guilford Press.

Mikels, J. A., \& Shuster, M. M. (2016). The interpretative lenses of older adults are not rose-colored-just less dark: Aging and the interpretation of ambiguous scenarios. Emotion, 16, 94-100. doi:10.1037/emo0000104 
Mikels, J. A., Shuster, M. M., Thai, S. T., Smith-Ray, R., Waugh, C. E., Roth, K.,...Stine-Morrow, E. A. (2016). Messages that matter: Age differences in affective responses to framed health messages. Psychology and Aging, 31, 409-414. doi:10.1037/pag0000040

National Center for Health Statistics. (2015). Health, United States, 2014: With special feature on adults aged 55-64. Hyattsville, MD: National Center for Health Statistics.

Parks, S. E., Housemann, R. A., \& Brownson, R. C. (2003). Differential correlates of physical activity in urban and rural adults of various socioeconomic backgrounds in the United States. Journal of Epidemiology and Community Health, 57, 29-35. doi:10.1136/jech.57.1.29

Plante, T. G., Gustafson, C., Brecht, C., Imberi, J., \& Sanchez, J. (2011). Exercising with an iPod, friend, or neither: Which is better for psychological benefits? American Journal of Health Behavior, 35, 199-208. doi:10.5993/ajhb.35.2.7

Reed, A. E., Chan, L., \& Mikels, J. A. (2014). Meta-analysis of the age-related positivity effect: Age differences in preferences for positive over negative information. Psychology and Aging, 29, 1-15. doi:10.1037/a0035194

Rothman, A. J., \& Salovey, P. (1997). Shaping perceptions to motivate healthy behavior: The role of message framing. Psychological Bulletin, 121, 3-19. doi:10.1037/0033-2909.121.1.3

Sherrington, C., Tiedemann, A., Fairhall, N., Close, J. C., \& Lord, S. R. (2011). Exercise to prevent falls in older adults: An updated meta-analysis and best practice recommendations. New South Wales Public Health Bulletin, 22, 78-83. doi:10.1071/NB10056
Simek, E. M., McPhate, L., Hill, K. D., Finch, C. F., Day, L., \& Haines, T. P. (2015). What are the characteristics of home exercise programs that older adults prefer?: A cross-sectional study. American Journal of Physical Medicine \& Rehabilitation, 94, 508-521. doi:10.1097/PHM.0000000000000275

Srivastava, P., \& Hopwood, N. (2009).A practical iterative framework for qualitative data analysis. International Journal of Qualitative Methods, 8, 76-84. doi:10.1177/160940690900800107

van Walraven, C., \& Hart, R. G. (2008). Leave 'em alone - why continuous variables should be analyzed as such. Neuroepidemiology, 30, 138-139. doi:10.1159/000126908

Whitehead, B. R., \& Blaxton, J. M. (2017). Daily well-being benefits of physical activity in older adults: Does time or type matter? The Gerontologist, 57, 1062-1071. doi:10.1093/geront/gnw250

Wilcox, S., Castro, C., King, A. C., Housemann, R., \& Brownson, R. C. (2000). Determinants of leisure time physical activity in rural compared with urban older and ethnically diverse women in the United States. Journal of Epidemiology and Community Health, 54, 667-672. doi:10.1136/jech.54.9.667

Wolinsky, F. D., Stump, T. E., \& Clark, D. O. (1995). Antecedents and consequences of physical activity and exercise among older adults. The Gerontologist, 35, 451-462. doi:10.1093/ geront/35.4.451

Yan, T., Wilber, K. H., Aguirre, R., \& Trejo, L. (2009). Do sedentary older adults benefit from community-based exercise? Results from the active start program. The Gerontologist, 49, 847-855. doi:10.1093/geront/gnp113 